\title{
2000 Years Transmission of Mathematical Ideas: Exchange and Influence from Late Babylonian Mathematics to Early Renaissance Science Yvonne Dold-Samplonius
}

"2000 Years Transmission of Mathematical Ideas" took place 8-12 May 2000 at the Rockefeller Foundation Bellagio Study and Conference Center, directed by Joseph W. Dauben (New York) and Yvonne Dold-Samplonius (Heidelberg). The purpose of the Bellagio conference was to bring together an international team of scholars, some of whom had worked together before, to allow thorough discussion of the transmission of mathematics between cultures across Europe and Asia. During an intensive week of lectures and discussion, participants focused their attention on early mathematical works, especially those in China, India, the Arabic/Islamic world, and the late Middle Ages/Renaissance in Europe, in order to explore evidence of direct and indirect influences, possible connections, and various means by which the problems or methods devised in one particular place and time found their way to other points, often very far apart in place and time.

The Rockefeller Foundation's Bellagio Conference Center, the Villa Serbelloni, provided a quiet, reflective atmosphere in which we were able to accomplish a substantial amount of work in a relatively short period of time. In the course of seven morning and afternoon sessions, twenty-one studies were presented and discussed in detail by the group. The list of participants with the abstracts of their contributions and e-mail addresses can be found at the 2000 Years Transmission of Mathematical Ideas website, http://www.iwr.uni-heidelberg.de/ transmath/

In response to the comments and suggestions made during the course of the meeting, the papers prepared for the Bellagio conference will be further revised over the next few months. The proceedings will appear as a volume of "Boethius", a series published by Steiner Verlag in Stuttgart, Germany. The Editorial Board is comprised of Joseph W. Dauben, New York, Yvonne Dold-Samplonius, Heidelberg, and Menso Folkerts, Munich.

First published in the NNJ online October 2000

\section{The reporter}

Yvonne Dold-Samplonius studied mathematics and Arabic at the University of Amsterdam, specializing in the History of Islamic mathematics. She wrote her thesis with Prof Bruins, Amsterdam and Prof. Juan Vernet, Barcelona. The academic year 1966-1967 she spent at Harvard studying under Prof. Murdoch. She has published about forty papers on the History of Mathematics. In the last years her interest has shifted to Mathematics in Islamic Architecture from a historic point of view. Under her supervision a video concerning this subject, in particular arches and vaults, has been produced at the IWR (Institute for Scientific Computing), Heidelberg. She is an associated member of this Institute. A second video, on reconstructing muqarnas (Stalactite vaults) is in progress. She presented "Calculations of Arches and Domes in 15 $5^{\text {th }}$ century Samarkand" at Nexus 2000. 